Original Article

\title{
Effect of proprioceptive neuromuscular facilitation integration pattern and swiss ball training on pain and balance in elderly patients with chronic back pain
}

\author{
Kim Jin Young ${ }^{1)}$, Choi Won Je'), Seo Tae $\mathrm{HwA}^{3)^{*}}$ \\ 1) Department of Occupational Therapy, Howon Univetsity, Republic of Korea \\ 2) Department of Physical Therapy, Hanlye University, Republic of Korea \\ 3) Department of Physical Therapy, Sanmu Heeling Medical Care Hospital: 223 Uncheonro, Seo-gu, \\ Gwangju 502-827, Republic of Korea
}

\begin{abstract}
Purpose] The purpose of this study was to determine the effects of proprioceptive neuromuscular facilitation integration pattern (PIP) and Swiss ball training on balance and pain in elderly patients with chronic low back pain. [Subjects] Participants were randomly assigned to a PIP training $(\mathrm{n}=24)$ and a Swiss ball training group $(n=24)$. [Methods] The training was performed for 30 minutes per day, three times a week for 6 weeks. Outcome measures included the mean velocity in the $\mathrm{X}$ and $\mathrm{Y}$ directions using the Good Balance System ${ }^{\circledR}$, functional reach test, timed up and go test, and visual analogue scale. [Results] After completion of training, mean velocity in the $\mathrm{X}$ and $\mathrm{Y}$ direction, and the functional reach test, timed up and go test, and visual analogue scale results showed statistically significant improvements in the PIP and Swiss ball training groups. However, there was no significant difference in the functional reach test, timed up and go test, and visual analogue scale results between the two groups. [Conclusion] This study indicated that PIP training improved the balance ability of elderly patients with chronic low back pain.

Key words: Back pain, Proprioceptive neuromuscular facilitation, Swiss ball
\end{abstract}

(This article was submitted Jun. 11, 2015, and was accepted Jul. 23, 2015)

\section{INTRODUCTION}

Chronic back pain primarily limits the range of motion and waist movement; moreover, it reduces trunk muscle strength, endurance, and flexibility. Due to these physical disabilities, patients with back pain experience difficulties in daily living and social activities, which may lead to mental and psychological problems such as reduction in the quality of life ${ }^{1)}$.

Bed rest; treatment using heat, ultrasound, electrical simulation, or traction; joint mobilization; manipulation; massage; and exercise therapy can be used as conservative treatment for back pain ${ }^{2)}$. However, passive treatments have been used less frequently in recent years. Instead, exercise treatment, which is an active treatment, has become a mainstream therapy for promoting early recovery and preventing recurrence or slowing progress toward chronic pain ${ }^{3)}$.

Most treatments for back pain in elderly individuals are

*Corresponding author. Seo Tae Hwa (E-mail: taihoa@, hanmail.net)

(C2015 The Society of Physical Therapy Science. Published by IPEC Inc. This is an open-access article distributed under the terms of the Creative Commons Attribution Non-Commercial No Derivatives (by-ncnd) License $<$ http://creativecommons.org/licenses/by-nc-nd/3.0/>. based on the use of medications such as analgesics, antiinflammatories, and muscle relaxants to relieve pain. Considering that the major cause of back pain is an imbalance of posture and muscles, such drug treatments may be helpful to temporarily relieve pain, but an exercise program that can help to correct posture in daily living should also be utilized for ultimate back pain management ${ }^{4}$.

Balance is the ability to maintain the line of gravity within the base of support of the body weight, and can be divided into static and dynamic balance ${ }^{5}$. Static balance refers to the ability to stand without postural sway on a fixed surface ${ }^{6}$. Balance ability is affected by various factors, including age, gender, cognition ability, musculoskeletal disorders, sensory disturbances, and muscle tone. A reduction in balance ability restricts the range of daily activities that patients can perform and increases the risk of falling ${ }^{7}$.

A proprioceptive neuromuscular facilitation integration pattern (PIP) is a proprioceptive neuromuscular facilitation (PNF)-applied cross training program that stimulates the proprioceptors in the muscles and tendons to improve their functions, as well as muscle activity, flexibility, and stability ${ }^{8)}$. If various patterns are applied simultaneously, more force can be used, thereby affecting muscle strength and stability further. Dietz proposed gait analysis and treatment by integrating individual patterns of PNF into the exercise pattern and motions occurring during the gait period ${ }^{9}$. PIP 
Table 1. General characteristics of the subjects

\begin{tabular}{|c|c|c|c|c|c|}
\hline & & \multicolumn{2}{|c|}{ PIP group $(n=24)$} & \multicolumn{2}{|c|}{ Swiss ball group $(n=24)$} \\
\hline & & Pre-test & Post-test & Pre-test & Post-test \\
\hline \multirow{3}{*}{ NSEO } & $\mathrm{X}$ axis $(\mathrm{mm} / \mathrm{s})$ & $7.65(1.63)$ & $6.14(1.44)^{* \dagger}$ & $9.28(2.60)$ & $8.30(2.49)^{*}$ \\
\hline & $\mathrm{Y}$ axis $(\mathrm{mm} / \mathrm{s})$ & $9.56(3.00)$ & $7.82(3.10)^{*}$ & $9.87(1.74)$ & $8.47(2.79)^{*}$ \\
\hline & Velocity moment $\left(\mathrm{mm}^{2} / \mathrm{s}\right)$ & $18.57(6.75)$ & $15.77(6.57)^{*}$ & $27.30(16.02)$ & $26.43(17.53)$ \\
\hline \multirow{3}{*}{ NSEC } & $\mathrm{X}$ axis $(\mathrm{mm} / \mathrm{s})$ & $8.77(1.92)$ & $6.83(1.54)^{*}$ & $11.53(3.30)$ & $10.67(4.28)$ \\
\hline & $\mathrm{Y}$ axis $(\mathrm{mm} / \mathrm{s})$ & $12.57(2.84)$ & $10.50(2.18)^{* \dagger}$ & $16.40(5.27)$ & $15.42(5.42)^{*}$ \\
\hline & Velocity moment $\left(\mathrm{mm}^{2} / \mathrm{s}\right)$ & $39.17(24.33)$ & $34.28(22.32)^{* \dagger}$ & $49.77(24.60)$ & $47.84(24.85)$ \\
\hline \multirow{3}{*}{ SSEO } & $\mathrm{X}$ axis $(\mathrm{mm} / \mathrm{s})$ & $13.33(4.31)$ & $10.35(3.50)^{*}$ & $16.47(5.62)$ & $13.87(6.94)^{*}$ \\
\hline & $\mathrm{Y}$ axis $(\mathrm{mm} / \mathrm{s})$ & $16.26(6.03)$ & $13.57(5.45)^{*}$ & $15.38(4.83)$ & $13.51(5.00)^{*}$ \\
\hline & Velocity moment $\left(\mathrm{mm}^{2} / \mathrm{s}\right)$ & $57.80(26.22)$ & $50.30(24.46)^{* \dagger}$ & $63.02(25.83)$ & $59.63(26.42)$ \\
\hline \multirow{3}{*}{ SSEC } & $\mathrm{X}$ axis $(\mathrm{mm} / \mathrm{s})$ & $23.78(7.13)$ & $18.78(5.50)^{* \dagger}$ & $31.54(9.63)$ & $28.45(9.51)^{*}$ \\
\hline & $\mathrm{Y}$ axis $(\mathrm{mm} / \mathrm{s})$ & $25.80(9.10)$ & $21.48(8.95)^{* \dagger}$ & $33.24(12.28)$ & $30.64(12.52)^{*}$ \\
\hline & Velocity moment $\left(\mathrm{mm}^{2} / \mathrm{s}\right)$ & $152.94(92.40)$ & $139.18(85.81)^{* \dagger}$ & $148.82(67.35)$ & $146.59(68.63)$ \\
\hline \multicolumn{2}{|c|}{ Functional reaching test $(\mathrm{cm})$} & $21.97(4.97)$ & $23.76(5.21)^{*}$ & $24.93(7.05)$ & $27.18(6.90)^{*}$ \\
\hline \multicolumn{2}{|c|}{ Timed up and go test (s) } & $21.49(8.93)$ & $18.60(7.43)^{*}$ & $21.82(8.21)$ & $20.15(8.70)^{*}$ \\
\hline \multicolumn{2}{|c|}{ Visual analogue scale } & $4.30(1.26)$ & $3.48(1.12)^{*}$ & $4.00(1.38)$ & $3.40(1.26)^{*}$ \\
\hline
\end{tabular}

aMeans (SD), *Significant difference within group, †'Significant difference between group

PIP: proprioceptive neuromuscular facilitation integration pattern, NSEO: normal standing eyes open, NSEC: normal standing eyes closed, SSEO: semi-tandem standing eyes open, SSEC: semi-tandem standing eyes closed

improves trunk stability and the proprioceptive senses of the limbs; moreover, it can improve static balance when it is applied for normal healthy persons ${ }^{10)}$. This study aimed to determine the effect of a PIP exercise program on pain relief and improvement in the balance ability of elderly persons with chronic back pain, as well as its applicability as a clinical therapeutic exercise program.

\section{SUBJECTS AND METHODS}

The subjects of this study were 48 elderly persons with chronic back pain who were admitted to an aged care hospital in G City. It was approved by the hospital, and all the participants provided written informed consent. The 48 subjects were randomly assigned to the PIP and Swiss ball training groups. The selection criteria were as follows: back pain for six months or longer, no back pain-related diseases or complications, no serious cardiopulmonary problems, and ability to exercise for $30 \mathrm{~min}$ or longer and walk $30 \mathrm{~m}$ or more without assistance. Table 1 summarizes the general characteristics of the study subjects who participated in the present research.

Subjects in the PIP training group were given pattern and return pattern training prior to the experiment by a specialized therapist who understood the integration pattern well. The Swiss ball exercise group carried out balance training on a Swiss ball. The sessions were 50 min long and were held three times a week for 6 weeks.

For static balance ability, the Good Balance System ${ }^{\circledR}$ (Metitur Oy, Palokka, Finland, 2003) was employed. Indexes that can represent static balance ability such as a shift in the center of pressure (COP) in the anterior-posterior direction, a shift of COP in the medial-lateral direction, and shift in the path of COP, were used to measure postural sway.
For the dynamic balance test, the functional reach test (FRT) and timed up and go (TUG) test were conducted. The FRT can measure an individual's balance and flexibility while performing tasks ${ }^{11)}$. Meanwhile, the TUG test measures the time it takes for an individual to rise from sitting in a standard arm chair, walk $3 \mathrm{~m}$, turn, walk back to the chair, and sit down ${ }^{12)}$. The visual analogue scale (VAS) was used to measure pain.

The data collected in this study were analyzed using SPSS statistical program for Windows version 18.0. A paired t-test was used to measure balance significance within groups, and analysis of covariance (ANCOVA) was used for comparison between groups. The level of statistical significance, $\alpha$, was set at 0.05 .

\section{RESULTS}

The results before and after the intervention are summarized in Table 1. In the normal standing eyes open (NSEO) posture, the PIP training group exhibited differences in mean velocity along the $\mathrm{X}$ and $\mathrm{Y}$ axes and velocity moment $(p<0.05)$. Meanwhile, the Swiss ball training group demonstrated a difference in mean velocity along the $\mathrm{X}$ and $\mathrm{Y}$ axes $(p<0.05)$. In the normal standing eyes closed (NSEC) posture, the PIP training group exhibited differences in mean velocity along the $\mathrm{X}$ and $\mathrm{Y}$ axes and velocity moment $(\mathrm{p}<0.05)$, while the Swiss ball training group showed a difference in mean velocity along the $Y$ axis $(p<0.05)$. In the semi-tandem standing eyes open (SSEO) posture, the PIP training group demonstrated differences in mean velocity along the $\mathrm{X}$ and $\mathrm{Y}$ axes and velocity moment $(\mathrm{p}<0.05)$. Furthermore, the Swiss ball training group exhibited a difference in mean velocity along the $\mathrm{X}$ and $\mathrm{Y}$-axes $(\mathrm{p}<0.05)$. In the semi-tandem standing eyes closed (SSEC) posture, the PIP training group 
demonstrated differences in mean velocity along the $\mathrm{X}$ and $\mathrm{Y}$ axes and velocity moment $(\mathrm{p}<0.05)$, while the Swiss ball group exhibited a difference in mean velocity along the $\mathrm{X}$ and $Y$ axes $(\mathrm{p}<0.05)$.

There were significant differences in the FRT, TUG, and VAS results before and after the PIP and Swiss ball exercises in both groups $(\mathrm{p}<0.05)$. A comparison within groups showed that there were significant differences in mean velocity along the $\mathrm{X}$ axis in the NSEO posture, mean velocity along the $\mathrm{Y}$ axis in the NSEC posture, velocity moment in the SSEO posture, and mean velocity along the $\mathrm{X}$ and $\mathrm{Y}$ axes and velocity moment in the SSEC posture $(p<0.05)$.

\section{DISCUSSION}

After 6 weeks of PIP and Swiss ball exercise treatment for elderly patients with chronic back pain, improvements in balance ability and reduction in pain were achieved. In a study on the application of a PNF integration pattern to stroke patients ${ }^{13)}, 18$ training sessions were conducted over 6 weeks. The results indicated a greater improvement in static and dynamic balance after PNF integration pattern exercises than after general exercise treatment. A study on 18 applications of a sprinter pattern lasting $30 \mathrm{~min}$ in patients with hemiplegia showed that a course of sprinter pattern exercise improved balance ability significantly more than in the control group, which carried out general exercise treatment ${ }^{14)}$. A study on back muscle strengthening training for 12 weeks also showed that the experimental group experienced a reduction in pain and the Oswestry Disability Index, as well as an increase in back muscle strength, in comparison to the control group ${ }^{15)}$. A study on PIP training and Swiss ball training applied to 40 patients with chronic back pain showed that the PIP training group experienced reduced pain and improved muscle activities to a greater extent than the Swiss ball training group ${ }^{16)}$. A study comparing PNF training and a trunk exercise program for chronic back pain patients showed that both groups improved in terms of balance ability, but the PNF group improved significantly more than the trunk exercise group.

For the Swiss ball exercise group, the FRT results were $24.93 \pm 7.05 \mathrm{~cm}$ and $27.18 \pm 6.90 \mathrm{~cm}$ before and after the exercise program, respectively, while for the PIP training group, the FRT results were $21.97 \pm 4.97 \mathrm{~cm}$ and $23.76 \pm 5.21 \mathrm{~cm}$ before and after the exercise. This indicates that both groups exhibited a significant difference in increases in distance, but no significant difference was shown between groups. A study on elderly persons divided into a PNF lower extremity pattern group and a control group for 4 weeks showed that the PNF group had a significantly higher FRT result, indicating that balance training using muscle strength enhancement was more effective in this group than in the control group, which is consistent with the present study result ${ }^{17}$.

In the comparison of TUG results, the PIP and Swiss ball exercise groups exhibited a significant difference in reduced TUG time before and after the exercise, but no significant difference between groups was observed. In a study using TUG in stroke patients divided into trunk stabilization and general balance exercise groups, both groups exhibited a significant difference before and after the exercise program, but no significant difference between groups was found ${ }^{18)}$. However, it reported that stroke patients' time to stand and walk was reduced significantly, thereby improving their dynamic balance ability. Geiger and Allen ${ }^{19)}$ reported that the TUG result reduced from $23.08 \pm 13.7 \mathrm{sec}$ before the exercise to $14.62 \pm 11.18 \mathrm{sec}$ after the exercise, which was consistent with the present study result. A study by Song et al. ${ }^{20)}$ reported that PIP training improved gait velocity in elderly persons who experienced a fall, and improved fall efficacy, indicating a positive effect of PIP training on these parameters.

The PIP and Swiss ball exercise group exhibited a significant reduction in the VAS score from before to after the exercise, but no significant difference between groups was observed. Based on the above results, PIP can induce significant improvements in balance ability and pain for elderly persons with chronic back pain.

In this study, psychological and physiological factors that can affect balance ability and pain, as well as daily activities, could not be controlled for completely, and within-subject factors that can influence balance ability and pain cannot be completely excluded. Thus, it is a limitation of this study that the results cannot be generalized to all elderly patients with chronic back pain. Nevertheless, the present findings showed that PIP training as a self-exercise program can provide foundational data for clinical use in both self-exercise programs and group exercise programs.

\section{REFERENCES}

1) Piironen $S$, Paananen M, Haapea M, et al.: Transcultural adaption and psychometric properties of the STarT Back Screening Tool among Finnish low back pain patients. Eur Spine J, 2015, [Epub ahead of print]. [Medline]

2) Maigne R: Diagnosis and treatment of pain of vertebral origin. Baltimore: Williams \& Wilkins, 1996.

3) Deyo RA: Acute low back pain: a new paradigm for management. BMJ, 1996, 313: 1343-1344. [Medline] [CrossRef]

4) Kasai R: Current trends in exercise management for chronic low back pain: comparison between strengthening exercise and spinal segmental stabilization exercise. J Phys Ther Sci, 2006, 18: 97-105. [CrossRef]

5) Wade MG, Jones G: The role of vision and spatial orientation in the maintenance of posture. Phys Ther, 1997, 77: 619-628. [Medline]

6) Ragnarsdóttir M: The concept of balance. Physiotherapy, 1996, 82: 368375. [CrossRef]

7) Jeong SM, Jwong BR, Yang SH: A study of correlation among balance, upper limb function and activities of daily living in stroke patients. Journal of Korean Entertainment Industrial, 2013, 9: 223-228.

8) Klein D, Stone W, Phillips W, et al.: PNF training and physical function in assisted-living older adults. J Aging Phys Act, 2002, 10: 476-488.

9) Dietz B: Let's Sprint, Let's Skate: Innovationen im PNF-konzept, Springer, 2009.

10) Choi WJ, Kim CK, Jeong DI, et al.: Change of the combined patterns of proprioceptive neuromuscular facilitation on static balance. J Korea Contents Assoc, 2008, 10: 251-258. [CrossRef]

11) Duncan PW, Weiner DK, Chandler J, et al.: Functional reach: a new clinical measure of balance. J Gerontol, 1990, 45: M192-M197. [Medline] [CrossRef]

12) Hughes $C$, Osman $C$, Woods A: Relationship among performance on stair ambulation, functional reach, and timed up and go tests in older adults. Issues Ageing, 1998, 21: 18-22.

13) Kim SJ: The effect of sprinter and skater pattern training of PNF on balance and gait ability in patients with Stroke. Graduate School of Daegu University, Master's thesis, 2011.

14) Jeong WS, Jeong JY, Kim CK, et al.: Effect of lower limb muscle activity on balancing through sprinter patterns of PNF. J Korea Contents Assoc, 2011, 11: 281-292. [CrossRef]

15) Choi G, Raiturker PP, Kim MJ, et al.: The effect of early isolated lumbar extension exercise program for patients with herniated disc undergoing 
lumbar discectomy. Neurosurgery, 2005, 57: 764-772, discussion 764 772. [Medline] [CrossRef]

16) Lee CW, Hwangbo K, Lee IS: The effects of combination patterns of proprioceptive neuromuscular facilitation and ball exercise on pain and muscle activity of chronic low back pain patients. J Phys Ther Sci, 2014 26: 93-96. [Medline] [CrossRef]

17) Jeon HJ, Lee MH: The effects of PNF technique versus trunk exercise program on the pain, disability, and balance in chronic LBP patients. J Korea Contents Assoc, 2009, 9: 665-673. [CrossRef]

18) Shin WS, Kim CY, Lee DY, et al.: The effects of trunk stability exercise on dynamic balance in the persons with chronic stroke. J Academia-industrial Technol, 2009, 10: 2509-2515.

19) Geiger RA, Allen JB, O'Keefe J, et al.: Balance and mobility following stroke: effects of physical therapy interventions with and without biofeedback/forceplate training. Phys Ther, 2001, 81: 995-1005. [Medline]

20) Song HS, Park SD, Kim JY: The effects of proprioceptive neuromuscular facilitation integration pattern exercise program on the fall efficacy and gait ability of the elders with experienced fall. J Exerc Rehabil, 2014, 10: 236-240. [Medline] [CrossRef] 